\title{
The Potential Role of PAGES in the IGBP Water Initiative
}

synthesis, and the co-ordinators associated with each theme are as follows:

1. The human rationale for the study of past environmental change (Oldfield).

2. The course of past climate change (Bradley).

3. Forcings and feedbacks operating on the physical climate system (Stocker/Alverson).

4. Biogeochemical/biospheric aspects and impacts of past global change (Boyle/Overpeck).

5. Future directions - this section will require input from all the others, as well as from senior colleagues external to the process. Jean-Claude Duplessy and Claude Lorius have agreed to share this responsibility.

The timetable proposed follows on from the brief workshop at the Fall AGU attended by several of the initial $\mathrm{CO}^{-}$ ordinators and other members of the PAGES community who were on the spot. Sub-group meetings are planned for the first 4 months of 1999 to shape and refine the contents of each section. The IGBP Congress in May 1999 will provide an opportunity to collate, present and evaluate the outlines of the book. At that stage, the shape and content will be endorsed by the PAGES Scientific Steering Committee (SSC). The next stage will be the main phase of writing, culminating in a final workshop to tie the whole text together during 2000. Ideally, both the book and certainly the glossy Executive Summary booklet should be available for the IGBP Open Science Meeting planned for Spring 2001. Towards the end of this period, we anticipate that the PAGES SSC will begin to review the status and future of the PAGES project as part of a broader review of IGBP as a whole.

The task of synthesis presents the PAGES community with a major challenge; perhaps the most daunting one yet. We shall try to keep the wider PAGES community abreast of the process through the newsletter and the website and we welcome your views on the scope, purpose and optimal outcome of the synthesis process.

\section{Frank Oldfield}

Executive Director, PAGES IPO, Bern, Switzerland oldfield@pages.unibe.ch

\section{A Proposed Integrative Inter-Project Inititative on Continental Aquatic Systems}

The primary goal of this initiative, as defined in the document approved by the IGBP SC, is to understand the role of continental aquatic systems in global biogeochemical cycles. The overarching question posed at the outset is: How have continental aquatic systems and the nutrient fluxes associated with them been and will be influenced by and responsive to global change, over past, present, and future time frames? Continental aquatic systems are defined as all surface and subsurface water involved in the hydrologic cycle on the continents. This includes lakes, rivers, wetlands, soil moisture, and ground water from the point where precipitation reaches the earth's surface until it reaches the sea in full marine conditions, or until it reaches some other final base level. The "downstream" boundary is a broad zone variable in space and time wherein river water interacts with the ocean before reaching fully marine characteristics with respect to chemistry and ecology. The emphasis of the project will be on water, sediment, carbon, nitrogen, phosphorus, silicon and micro nutrients.

\section{Past Biogeochemistry and Paleoecology}

Continental aquatic systems are rich in natural archives of past biogeochemical states and fluxes. These take the form of lake, reservoir and near-shore marine sediments, ground waters and accumulated wetland sediments and peats. Analyses of such archives can provide insight into both the past biogeochemistry of the systems studied and of the changing conditions of climate, vegetation, soils and human land use to which changes in aquatic biogeochemistry are linked. They can document the impact of biogeochemical changes on the nature and functioning of aquatic ecosystems in the past. In addition, paleo-records can provide information on the pristine state of drainage basins which are now severely altered by human activity, and thus out of biogeochemical and ecological equilibrium.

Currently available evidence suggests that even in long-settled and highly developed areas of the world, (e.g. Western Europe), the main changes in aquatic biogeochemistry have taken place within the last 150 to 200 years, despite the fact that agriculture, deforestation and local settlement began centuries and, in many cases, millennia before this. The main initial forcing factors seem to have been population growth, urbanization, industrial development and the construction of integrated sewer systems. Current forcing increasingly reflects the impact of nonpoint agricultural sources for $\mathrm{N}$ and $\mathrm{P}$. It may be that further evidence from longsettled areas, in Eurasia and the Mediterranean region for example, will build a case for a more flexible time frame, but we believe that the main focus should be on the last 200 years. This has the added advantage of being compatible with the time frame prioritized by LUCC and GCTE for reconstructing past land cover and terrestrial ecosystems. Moreover, chronologies of sedimentation can often be provided for most of this period, using radiometric techniques such as ${ }^{210} \mathrm{~Pb}$. There are also opportunities for quantitative calibration over this time interval, through comparison with direct observations during the most recent period.

Recent research confirms that paleolimnological studies can track past atmospheric contamination using the record of metal and fly ash deposition. The fossil record in the sediments can be used as a basis for reconstructing past water quality, including changes in $\mathrm{pH}$, with a high degree of precision. It can also be used to reconstruct past $\mathrm{P}$ loadings to a reasonable level of approximation. More research is required to establish the degree of confidence with which it may become possible to reconstruct past changes in $\mathrm{N}$ and $\mathrm{Si}$ concentrations and fluxes from sedimentary evidence. Records of past particulate inputs are often extremely well preserved in and quantifiable from the sedimentary record and these are of special importance where nutrient delivery and sequestration are particle-associated. At the same time, sediment studies allow calculation of bulk catchment yields and sediment source ascription in ways that can be directly related to soil and terrestrial ecosystem processes, such as accelerated erosion and deforestation.

\section{Lake Sediments and Past Climate}

There is growing evidence to show that paleolimnological research can provide robust reconstructions of climate varia- 
bility and of the sensitivity of aquatic ecosystems to such variability. Since both natural variability, including extreme events, and anthropogenic forcing will contribute interactively and in as yet unknown proportions to future climate changes, it is important to understand the links between natural climate variability and aquatic ecosystem response. For this, a longer time scale than the last 200 years will be needed. Case studies spanning the last 1000 to 6000 years are therefore envisaged and these will also have the advantage of including the time frame of direct interest to the PAGES Focus 3 initiative on the Human Impact on Fluvial Systems since the beginning of Agriculture (LUCIFS - see PAGES Newsletter 98-1). The information generated by these studies will provide a more realistic view of preindustrial base-line conditions and of the sensitivity of aquatic systems to the temporal pattern of natural variability.

High resolution, near-shore marine sediments with a major terrigenous component can provide paleorecords broadly comparable to those available through lake sediment studies. In addition, they can be used to document the impact of changing sediment and biogeochemical fluxes on marine and coastal ecosystems.

\section{Ground Water, Mountains and Wetlands}

Ground water forms a major human resource. Under favorable conditions, ground waters (unsaturated zone as well as saturated zone environments) may also act as an archive of climatic and environmental change. This information is obtained from conservative chemical species, noble gas ratios and isotopic signatures. This archive is the only other indicator, apart form ice cores, which may store water directly from former times. The ground water archive not only helps to quantify source contributions, ground water age, recharge rates and the future consequences of abstractions, but also human impacts from diffuse and point source contamination. Currently available research methods include the tools for understanding the fluxes of nutrients and contaminants between surface and ground waters, the role of ground waters as both sources and sinks and the future consequences of present and projected levels of exploitation.

In many upland areas and in regions dependent on the capacity of the world's mountains to store and deliver water for human use, glaciers and snow fields form an important part of the aquatic system. The response of these to recent climate change and their vulnerability under conditions of predicted global warming is a further area of concern into which paleodata can shed light.

Wetlands also contain paleo-records from which their role as biogeochemical sinks and sources, both of nutrients and trace gases can be reconstructed. Growing acknowledgment of the importance of wetlands in geochemical cycling and environmental management points to the need to exploit these systems as archives of recent changes in nutrient flux and sequestration rates.

\section{Summary}

In summary, sedimentary and other paleorecords can help to quantify the role of natural variability and human impacts on biogeochemical cycling in the continental aquatic component of the earth system, on a catchment, regional and, potentially, a global scale. They can provide information on base-line conditions and realistic management targets in amelioration programs. In addition, they can put present day observations, data sets and experiments in a realistic, dynamic context that acknowledges the role of changing forcing mechanisms in the fluxes, stocks and concentrations of at least some nutrients. In so doing, paleo-research also provides an essential tool in model development and validation.

The PAGES SSC has approved in principle the establishment of a new Activity within 'Focus 3' (Human Interactions in Past Environmental Changes). This Activity, to be led by Rick Battarbee, University College London, has been entitled "human impact on lake ecosystems and the role of palaeolimnology" (LIMPACS). One of the tasks for LIMPACS will be to link with and contribute to the IGBPwide 'Water' initiative and thereby ensure that it serves the needs of both PAGES and the IGBP community as a whole.

\section{Frank Oldfield}

Executive Director, PAGES IPO, Bern, Switzerland oldfield@pages.unibe.ch

The above report is a modified extract from the IGBP briefing document on "Continental Aquatic Systems".
PEP I

\section{New Leader}

Geoff Seltzer, professor of Quaternary Geology and Geomorphology, Dept. of Earth Sciences,

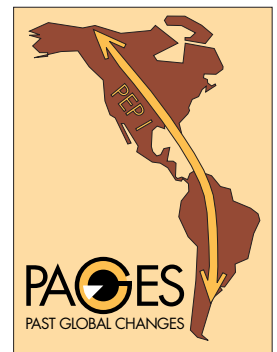

Syracuse University, has taken over the leadership of the PEP I transect from Vera Markgraf. Geoff's research focuses on the glacial and climatic history of the Andes of Ecuador, Peru, and Bolivia. Specifically, he is developing high resolution (centennial to millennial scale) records of climate change for the late Quaternary (last 20,000 years). The development of such proxy records provides the primary means by which hypotheses are generated and tested regarding the patterns and mechanisms for global climate change during the Quaternary. Recent research projects that Geoff has been involved with include: the history and climatic interpretation of glaciation in the Bolivian Andes, the pollen stratigraphy of lake cores and its relevance to changes in vegetation and climate, the physical sedimentology of glacial lakes in the central Andes, relict ice deposits in saline lakes of southwestern Bolivia and their relevance to issues of regional climate change and the Holocene record of lake level change in the Bolivian cordillera from cores of lacustrine sediments. His future research projects in the Andes include: high resolution glacial geologic and palynologic studies of the Ecuadorian and Peruvian Andes, the sedimentology of Lake Titicaca as a potential high-resolution and long-term climate record from the tropics, the use of cosmogenic isotopes in surface dating of moraines in the Bolivian Andes and stable isotope stratigraphy of marlrich lakes in the Peruvian Andes. Geoff has an exciting set of plans building on the success of the recent PEP1 meeting on interhemispheric patterns of climate change in the Americas (Merida, March 1998) and complementing the ongoing PEP I synthesis project. His goals for PEP I will be the subject of a future PAGES newsletter report.

\section{Keith Alverson}

Science Officer, PAGES IPO, Bern, Switzerland alverson@pages.unibe.ch 